\title{
Analysis of the Correlations Between Visual Mathematics Literacy Perceptions, Reasoning Skills on Geometric Shapes and Geometry Performances of Pre-Service Mathematics Teachers
}

\author{
Aziz ILLHAN* \\ Assistant Professor, Munzur University, Çemişgezek Vocational School, Tunceli, Turkey \\ ORCID: 0000-0001-7049-5756
}

\section{Recep ASLANER}

Professor Dr., Inonu University, Education Faculty, Malatya, Turkey, ORCID: 0000-0003-1037-6100

\begin{tabular}{l}
\hline \hline Article history \\
\hline Received: \\
17.04 .2020 \\
Received in revised form: \\
15.09 .2020 \\
Accepted: \\
15.09 .2020 \\
Key words: \\
\hline Geometry performance, \\
Path analysis, \\
Pre-service mathematics \\
teachers, \\
Reasoning skills on geometric \\
shapes, \\
Visual mathematics literacy \\
perception.
\end{tabular}

In the study, the correlations between visual mathematics literacy perceptions, reasoning skills on geometrical shapes and geometrical performances of pre-service mathematics teachers were investigated. The study participants included 384 pre-service mathematics teachers, who were attending education departments in two universities located in Eastern and Southeastern Anatolia regions in Turkey. In the study, due to time and workforce limitations, convenience sampling method was preferred, and relational screening model was adopted. The study data was collected with visual mathematics literacy perception scale, reasoning skills on geometric shapes and geometry performance tests developed by the authors. Analysis of the correlation between the variables demonstrated that there was a moderate correlation between visual mathematics literacy perception and both the reasoning skills on geometrical shapes and the geometry performance, and there was a high correlation between the reasoning skills on geometric shapes and geometry performance. Primary model path analysis demonstrated that visual mathematics literacy perception had a moderate effect on reasoning skills on geometrical shapes and geometry performance. It was also determined that reasoning skills on geometric shapes had a strong effect on geometry performance. The findings of the path analysis conducted on the sub-dimensions revealed that all sub-dimensions had a moderate positive effect on reasoning skills on geometric shapes. It was also found that visual mathematics literacy perception had a moderate positive effect on visual perception, geometry knowledge, spatial intelligence and concretization subdimensions and geometry performance.

\footnotetext{
* Correspondency: ailhan@munzur.edu.tr. Phone: +90 5548291021
} 


\section{Introduction}

Review of the historical development of mathematics, which was described as one of the dimensions of mathematics literacy, would demonstrate that visuals contributed significantly to the emergence, development, instruction and transfer of mathematics to future generations. The first mathematical knowledge was reflected on cave walls using images or pictures and transferred to next generations through visuals (Alpan, 2008). Since visual concepts constitute a different source in mathematical thinking when compared to lingual thinking or traditional algebra, they could be considered as a powerful and alternative source for mathematical solutions of the students (Konyalığlu, 2003). During the last century, visuality became significant especially in the field of education. Visuality is expressed with the concept of visual literacy in scientific literature, and in mathematics it was defined as the visual mathematics literacy perception (Bekdemir \& Duran, 2012). Visual mathematics literacy perception was defined by Duran and Bekdemir (2013) as the skill to perceive, express, interpret, assess and utilize the problems encountered in daily life spatially or visually and the skill to perceive, express, interpret, assess and utilize spatial or visual information mathematically. In other words, visual mathematics literacy perception was described as the skills of an individual to understand mathematical problems encountered in daily life with two or more dimensional visuals, and to interpret the information containing these visuals using mathematical expressions based on the logical framework of the mathematics (Illhan, 2019).

The concept of reasoning, which is associated with the field of mathematical learning, was described as a process of thinking and reaching a rational conclusion based on all relevant factors. The individual who can reason about a topic has adequate knowledge on the topic, and discovers, analyzes, makes logical predictions or conclusions, justifies her or his ideas, reaches certain conclusions, could defend and explain the conclusions on a case that she or he encountered for the first time (Umay, Duatepe, \& Akkuş-Çıkla, 2005). The concept of reasoning is also described as a cognitive process where individuals receive information and produce a new and original inference (Kurtz, Gentner, \& Gunn, 1999). Baykul (2014, p. 57) defined the concept of reasoning as the ability to think thoroughly and making a decision. Furthermore, the concept of reasoning was described by IIlhan (2019) as the skill to find a previously undiscovered or unthought method or to make an inference based on all data available about an encountered problem. Two of the required skills in order to realize the aim of preparing the students for life as described in MoNE (2018) middle school mathematics curriculum were; problem solving and reasoning skills. The process of learning mathematics is prominent for the development of the cognitive skills of the students (Özsoy, 2005, p. 180). The concept of mathematical reasoning was described in the MoNE (2013, p. 5) middle school mathematics curriculum as the process of creating new knowledge using mathematical instruments (definitions, symbols, correlations, etc.) and thinking techniques (deduction, induction, comparison, generalization, etc.) based on available data.

The geometry sub-learning area in mathematics curriculum includes topics that aim to help learners to develop spatial reasoning skills (MoNE, 2018). The concept of spatial reasoning was defined as observing or understanding the imaginary movements of objects especially in the three-dimensional space (Clements \& Battista, 1992). The concept of spatial ability includes skills related to the use of geometric form and space (Olkun, 2003). Moreover, spatial ability has two sub-dimensions: spatial visualization and spatial relations (Battista, 1994). Review of the tests developed to measure reasoning skills would demonstrate that the students are asked to determine which of the given objects is the transformed or rotated form of the figure initially displayed (Pellegrino, Alderton, \& Shute, 1984). Spatial visualization entails imagining new forms that were the results of moving two or three dimensional objects that include one or more 
parts or parts of these objects in three dimensional space (Olkun, 2003). In general, it was argued that spatial thinking had a positive and strong relationship with mathematical thinking. Thus, in an intuitive sense, it was reported that an improvement in spatial thinking would lead to the development of mathematical thinking (Battista, 1994).

The curricula that guide the instruction process and include the basic elements of this process are constantly revised in order to fulfill the requirements of the era. Thus, since 2004-2005 academic year, the curricula include both conventional measurement tools and performancebased measurement tools (MoNE, 2005; 2009; 2011; 2013; 2018). Particularly in the evaluation and measurement section of the last two mathematics curricula revisions conducted in 2013 and 2018, the importance of performance-based measurement was emphasized (MoNE, 2013; 2018). It can be argued that one of the most utilized alternative measurement tools in mathematics instruction is performance evaluation (Bal, 2012). In the use of performance evaluation approach in the instruction process, problem solving processes, skills and directly observable attitudes or behavior are emphasized. In mathematics, performance sometimes involves paper-and-pencil applications such as solving an equation of the second order. The advantage of performance measurement is its high level of validity when applied correctly (Webb, 1993). McMillian (2004) described performance as the products that were formed by the combination of knowledge and skills in different areas and on topics that were instructed to the students either individually or in groups, or on selected topics. The main objective of performance evaluation is to determine cognitive, affective and psychomotor skills of the students such as reading comprehension, critical thinking, collaboration, problem solving, research, creativity and communication (MoNE, 2018). Pajares and Kranzler (1995) reported that there was a strong correlation between mathematical abilities and mathematical problemsolving skills of the students when cognitive skills were controlled.

Based on the general objectives and basic principles depicted in the Basic National Education Code No. 1739, three objectives of the mathematics curriculum were set out as follows: the student should be able to improve and use mathematical literacy skills effectively, should be able to utilize reasoning and personal thoughts in problem solving comfortably, should be able to recognize the deficiencies, inaccuracies or gaps in other individuals' mathematical reasoning, should be able use mathematical language and terminology accurately to share and explain mathematical ideas within the context of logic (MoNE, 2018). Communication and reasoning skills were the first two skills that the students should acquire according to the curriculum. In the curriculum, which emphasized that reasoning has a one-to-one relationship with mathematics learning areas, communication skills were also stressed (MoNE, 2018). It was observed that the indicators that should be considered in communication skills corresponded to the basic skills of literacy, mathematics literacy and visual mathematics literacy perception. Besides, in the measurement and evaluation section of MoNE (2018) mathematics curriculum, it was pinpointed that performance-based evaluation should be prioritized in the instruction process. It was stated in the curriculum that these concepts were important for both the students and the instructors.

The curricula are undoubtedly roadmaps for the instructors, and it was stipulated that the skills included in these roadmaps should first be possessed by the instructors. The special area competencies for mathematics teachers described by the MoNE Board of Education and Training enacted with the approval of the Minister's Office on 25 July 2008 (No. 2391). As a result of this decision, certain special area competencies that mathematics teacher candidates should have were; creating a learning environment where students could express, write and communicate their emotions and thoughts on mathematics freely, developing the skill to utilize 
mathematical communication using written, visual and verbal forms, developing students' associative and reasoning skills, ability to conduct performance evaluation on the development level of the skills of each student, ability to use geometry knowledge during the instruction process actively (MoNE, 2017).

The learning areas in the middle school mathematics curriculum include the geometry learning area. Geometry achievements are included in all grade levels in the middle school mathematics curriculum. However, it was observed that mathematics and geometry achievements were very low in international exams such as PISA and TIMMS and in national exams such as LKS and YKS. Literature review revealed that teachers did not prioritize geometry instruction in Turkey, students' geometry achievement levels were related to the geometry achievement levels of teachers, the knowledge they acquired in undergraduate programs on the concept of visual literacy and their professional experiences was not sufficient to conduct visual literacy applications in their classes, and the geometrical thinking levels of pre-service teachers attending faculties of education were lower than expected (Chen, Dipinto, \& Newman, 2017; Durmuş, Toluk-Ucar, \& Olkun, 2002; Erdogan, 2006; İlhan, 2015; Özdemir, Duran, \& Kaplan, 2015; Paksu, 2013; Şahin, 2008). Together with that, literature review demonstrated that the reasoning skills of the students, teachers or pre-service teachers on geometric shapes were low, they did not have sufficient knowledge on visual mathematics literacy perception, there was a significant correlation between mathematical thinking skills of the teachers and mathematics literacy performance of the students, there was a significant correlation between visual mathematics literacy perception and problem solving skills, and the teachers lacked geometry content knowledge or it was important to measure their geometry performance levels (Amsterlaw, 2004; Baki, 2001; Bekdemir \& Duran, 2012; Çalışkan, 2016; Gallant, 2009; Hohenwarter \& Preiner, 2007; Jadallah, 2009; Oaksford, 2005; Şahin, 2005). Also, due to the fact that there are only a few studies on these skills of pre-service mathematics teachers, it was considered that these skills were correlated and the correlation between them should be investigated, the present study was considered important. That being said, there was no study that analyzed the correlations between visual mathematics literacy perception, reasoning skills on geometric shapes and geometry performance with the analysis methods used in the present study (correlation and path analysis) using original scales and tests, and with pre-service mathematics teachers in the literature. Thusly, it was considered that the present study would have unique value and would contribute to mathematics education.

\section{The Aim of the Study}

The aim of the present study was to investigate the correlation between Visual Mathematical Literacy Perceptions (VMLP), Reasoning Skills on Geometric Shapes (RSGS) and Geometry Performances (GP) of pre-service mathematics teachers. Based on this general aim, the following sub-problems were established: For pre-service mathematics teachers;

(1) Is there a correlation between VMLP and sub-dimensions, and RSGS and GP?

(2) What is the effect size between VMLP, RSGS and GP?

(3) What are the effect size values between VMLP sub-dimensions, RSGS and GP?

(4) What are the direct, indirect, and total effects of VMLP and sub-dimensions on RSGS?

(5) What are the direct, indirect, and total effects of VMLP and sub-dimensions on GP? 


\section{Method}

\section{Research Model}

In the present study, structural equation model was used to determine the correlations between VMLP, RSGS and GP levels of pre-service mathematics teachers. Currently, structural equation model is used extensively in solving educational problems (Keskin, 1998). When correlated variations in two or more variables are investigated, it is possible to argue that there is a correlation between the distributions in the presence of similarity between the variations. The correlation between the studied variables is usually a cause and effect relationship (Kocakaya, 2008). The correlation coefficient that explains the covariation in two variables could also demonstrate the effect of other possible variables except the correlated variables. In order to analyze the complex causal system in such cases, it is necessary to demonstrate the effect of the possible variables that are considered to affect the variables of interest simultaneously. It is not possible to explain such a causal system with correlation analysis. In order to explain and interpret the correlations between variables in such cases, relational screening model, an application of the structural equation model, is applied (Karadağ, Baloğlu, \& Küçük, 2010). In relational screening model, the interactions between the variables that are expected to have causality are presented using structural equation diagrams. In structural equation model, after the variables, the effects of which were desired to be observed, are placed, all effects of the external variables on internal variables are indicated by unidirectional arrows. The correlations between the other system variables and unrelated variables are indicated by two-directional arrows and drawn in the form of correlating curves. Numerical expressions that reflect structural equation model coefficients are written on the diagram. The values of simple correlation coefficients are written on the two-directional curves (Kocakaya, 2008). Thus, in the present study, relational screening model was used to determine the presence and the degree of the covariance between the correlation of more than two variables (Karasar, 1999). In the primary model, the external variable was determined as VMLP and the internal variables were determined as RSGS and GP. Furthermore, in the model for the sub-dimensions structured based on the variables, external variables were determined as Visual Perception (VP), Geometry Knowledge (GK), Spatial Intelligence (SI), Concretization (CON) and Pattern Formation (PF) sub-dimensions, while internal variables are determined as RSGS and GP.

\section{Study Participants}

The participants of the study included 384 pre-service mathematics teachers $(252$ female and 132 male students) attending education departments in two medium-sized universities in Eastern and Southeastern Anatolia during the 2016-2017 academic year fall semester. In the study, due to time and workforce limitations, convenience sampling method was preferred in determination of the study sample. In convenience sampling method, due to time, labor and economic constraints, the sample is selected from a convenient and easily accessible population (Büyüköztürk, 2015, p. 92). The participant demographics (gender, class and university) are presented in Table 1.

Table 1. Participant demographics

\begin{tabular}{lllllll}
\hline University & Gender & Freshmen & Sophomore & Junior & Senior & Total \\
\hline \multirow{2}{*}{ University I } & Female & 33 & 39 & 41 & 36 & 149 \\
& Male & 20 & 13 & 9 & 16 & 58 \\
\multirow{2}{*}{ University II } & Female & 27 & 33 & 24 & 19 & 103 \\
& Male & 22 & 13 & 16 & 23 & 74 \\
\hline Total & & 102 & 98 & 90 & 94 & 384 \\
\hline
\end{tabular}


It was reported that the data must meet the normality assumption for structural equation modeling analysis, factor analysis and confirmatory factor analysis. In order to meet this assumption, the sample size should be between 100-150 (Güleş, Akgemci, \& Türkmen, 2011). Also, literature review demonstrated that there were different views on the minimum sample size required for structural equation model data analysis (Bentler \& Chou, 1987; Hair, Black, Babin, \& Anderson, 1998; Jayaram, Kannan, \& Tan, 2004; Kline, 2011). The most accepted view in these resources was that the sample size should not be below 200 (Kline, 2011). As seen in Table 1, 384 pre-service mathematics teachers participated in the present study. Thus, it can be suggested that the number of pre-service mathematics teachers included in the study was sufficient to meet the multiple normality assumption in the applied model.

\section{Data Collection Instruments}

Visual Mathematics Literacy Perception Scale:

The visual mathematics literacy perception scale developed by İlhan (2015) includes 37 positive Likert-type items. The scale includes five sub-factors: VP, GK, SI, CON and PF. Cronbach's alpha internal reliability coefficient was 0.904 for the scale. The lowest possible score in the VMLP scale is 37 and the highest possible score is 185.

\section{Reasoning Skills Test on Geometric Shapes:}

The test developed by İlhan and Aslaner (2018) includes 20 multiple choice items. Correct RSGS test answers are scored with 1 and incorrect answers are scored 0 . Therefore, the lowest possible score in the RSGS test is 0 and the highest possible score is 20 . For the validity of the RSGS test, highly preferred content and construct validity tests were conducted. In determining the construct validity of the RSGS test, it was considered adequate and sufficient to get views of the field experts. RSGS test content validity was conducted with the analysis of geometry instruction course learning outcomes in Turkish universities and with a literature review study. After the test was developed, the reliability coefficient was calculated, and it was found that KR-20 reliability coefficient was 0.745 . This value was sufficient to argue that the test was reliable (Büyüköztürk, 2015, p. 167).

\section{Geometry Performance Test:}

GP test was developed with the analysis of learning outcomes in geometry instruction course given in Turkish universities and with a conducted literature review. The draft test was assessed by three faculty members in mathematics education department and one faculty member in Turkish language education department. In order to determine interrater reliability, the KAPPA coefficient was calculated. The obtained KAPPA coefficient was 0.90 and it was concluded that the fit ([KAPPA]> 0.75) was excellent (Kılıç, 2015). For the GP test, a graded scoring key was developed and each question was scored as "Null", "False", "Partially True" and "True". Based on this evaluation, full correct answers were scored 2 points, partially correct answers were scored 1 point, false and blank answers were scored 0 points and a pilot scheme was conducted to determine the validity and reliability of the test. For the validity of the GP test, highly accepted content and construct validities were tested. To determine the construct validity, item difficulty and distinctiveness indices were calculated the views of field experts were obtained for content validity, geometry instruction course outcomes in Turkish universities were analyzed and literature review was conducted. The reliability of the 38-item final GP test developed by the author was determined with KR-21 reliability coefficient. It was found that the KR-21 reliability coefficient for the test was 0.791 . Büyüköztürk (2015) reported 
that KR-21 internal reliability coefficient should be greater than 0.70 for a test to be considered as reliable. The calculated value indicated that the test was reliable.

\section{Data Analysis}

Statistical analyzes were conducted after the quantitative data was converted into Office Microsoft Excel, SPSS 23.0 and Lisrel 8.80 files. In the study, correlation coefficients and $p$ significance values were used during the correlation analysis, and the data were analyzed using path coefficients during the path analysis stage. When calculating the effects of external variables on internal variables, direct, indirect and total effect sizes were used. While validating structural equation models, $x^{2} / s d$, RMSEA, GFI, AGFI, RMSR, SRMSR, CFI and NNFI values were calculated.

\section{Findings and Interpretations}

In the study, initially, the correlations between the variables were determined. Matrices for the correlations between the variables were constructed and the findings are presented in Table 2.

Table 2. Variable correlation matrix

\begin{tabular}{lllllllll}
\hline Variables & VP & GK & SI & CON & PF & VMLP & RSGS & GP \\
\hline VP & - & & & & & & & \\
GK & $0,62^{* *}$ & - & & & & & & \\
SI & $0,66^{* *}$ & $0,68^{* *}$ & - & & & & & \\
CON & $0,67^{* *}$ & $0,72^{* *}$ & $0,67^{* *}$ & - & & & & \\
PF & $0,58^{* *}$ & $0,79^{* *}$ & $0,60^{* *}$ & $0,65^{* *}$ & - & & & \\
VMLP & $0,87^{* *}$ & $0,89^{* *}$ & $0,83^{* *}$ & $0,85^{* *}$ & $0,79 * *$ & - & & \\
RSGS & $0,51^{* *}$ & $0,51^{* *}$ & $0,53^{* *}$ & $0,54^{* *}$ & $0,53^{* *}$ & $0,62^{* *}$ & - & \\
GP & $0,39^{* *}$ & $0,37^{*}$ & $0,40^{* *}$ & $0,41^{* *}$ & $0,33^{*}$ & $0,45^{* *}$ & $0,80^{* *}$ & - \\
\hline
\end{tabular}

(**: $\mathrm{p}<0,01$ and $*: \mathrm{p}<0,05)$

Review of Table 2 would demonstrate that the correlations between the variables were positive and significant for $\mathrm{p}<0.01$ and/or $\mathrm{p}<0.05$. Significant correlations were determined between VP and GK, and VP and PF at $\mathrm{p}<0.05$ level, and between the other variables at $\mathrm{p}<0.01$ and $\mathrm{p}<0.05$ levels. Analysis of the correlation between VMLP and its sub-dimensions demonstrated that the highest correlation was between VMLP and GK $(r=0.89, \mathrm{p}<0.01)$. Furthermore, there was a moderate correlation between VMLP and RSGS $(r=0.62, p<0.01)$, moderate correlation between VMLP and GP $(\mathrm{r}=0.45, \mathrm{p}<0.01)$ and high correlation between RSGS and GP $(\mathrm{r}=0.80$, $\mathrm{p}<0.01)$. In the study, main and sub-dimension effect sizes were analyzed, and the obtained path coefficients and correlations are presented in Figures 1 and 2.

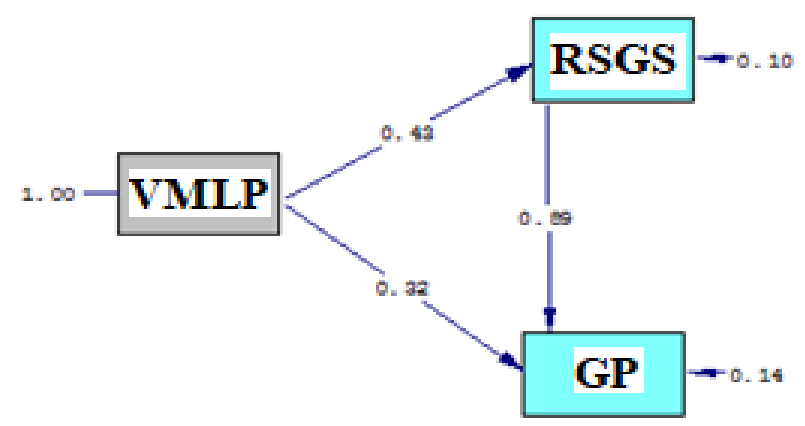

Figure 1. Standardized path coefficients for the primary model 
Suhr (2009) determined that when the path analysis coefficients were smaller than 0.10, then the effect was weak, and when the path analysis coefficients were between 0.10 and 0.50 , then the effect was moderate, and when the path analysis coefficients were greater than 0.50 , then the effect was strong. Thereupon, review of Figure 1 would demonstrate that there was a moderate effect between VMLP and RSGS $(\beta 1=0.43)$ and between VMLP and GP $(\beta 1=0.32)$, and there was a quite string effect between RSGS and GP $(\beta 1=0.89)$. However, $t$ values between the primary model variables were significant at $\mathrm{p}<0.01$ [VMLP-RSGS $(\beta 1=0.43, \mathrm{p}=0.00$ $<0.01)$; VMLP-GP $(\beta 1=0.32, \mathrm{p}=0.00<0.01)$; RSGS-GP $(\beta 1=0.89, \mathrm{p}=0.00<0.01)]$.

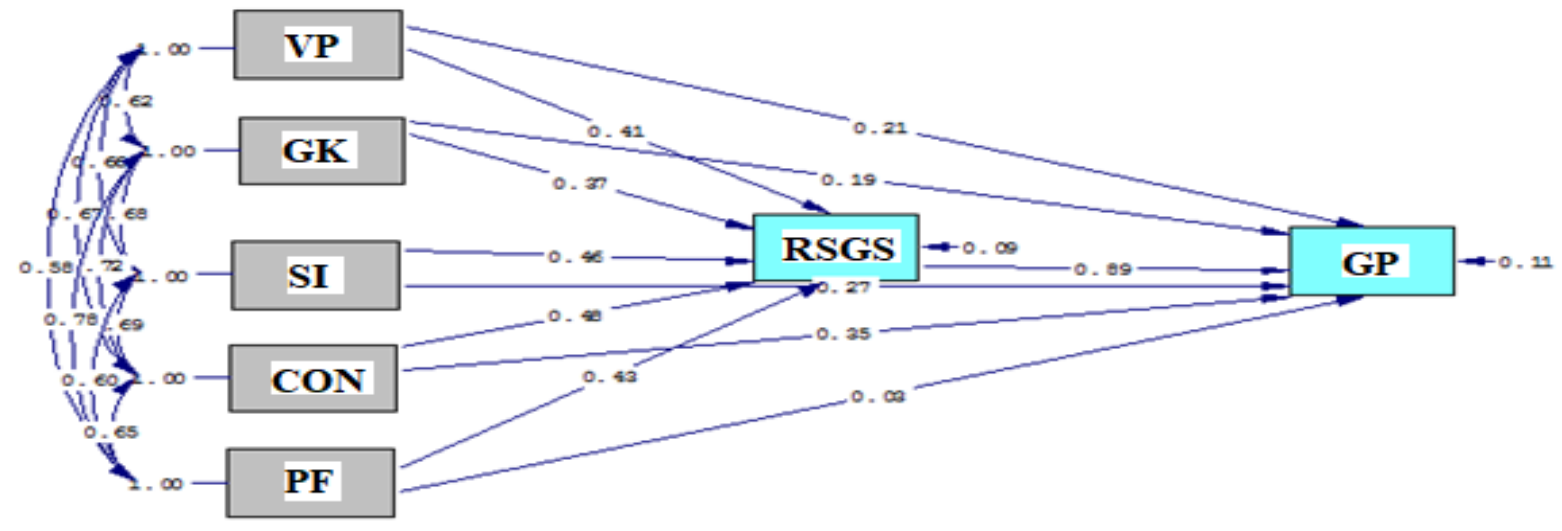

Figure 2. Standardized path coefficients for sub-dimension model

Review of Figure 2 would demonstrate that there was a positive and significant effect between all sub-dimensions of VMLP and RSGS [VP-RSGS $(\beta 1=0.41, p=0.00<0.01)$; GK-RSGS $(\beta 1=0.37, \quad \mathrm{p}=0.00<0.01) ; \quad$ SI-RSGS $\quad(\beta 1=0.46, \quad \mathrm{p}=0.00<0.01) ; \quad$ CON-RSGS $\quad(\beta 1=0.48$, $\mathrm{p}=0.00<0.01)$; PF-RSGS $(\beta 1=0.43, \mathrm{p}=0.00<0.01)]$, while there was an insignificant effect between PF sub-dimension and GP $[\beta 1=0.03, p=0.12>0.01]$ and there were positive and moderate effects between GP and the other sub-dimensions [VP-GP $(\beta 1=0.21, p=0.00<0.01)$; GK-GP $\quad(\beta 1=0.19, \quad p=0.00<0.01) ;$ SI-GP $\quad(\beta 1=0.27, p=0.00<0.01) ; \quad$ CON-GP $\quad(\beta 1=0.35$, $\mathrm{p}=0.00<0.01)]$. To that end, the PF-GP path analysis was removed and the path analyzes were recalculated and the model was organized with the new values. The new model and path analysis coefficients are presented in Figure 3.

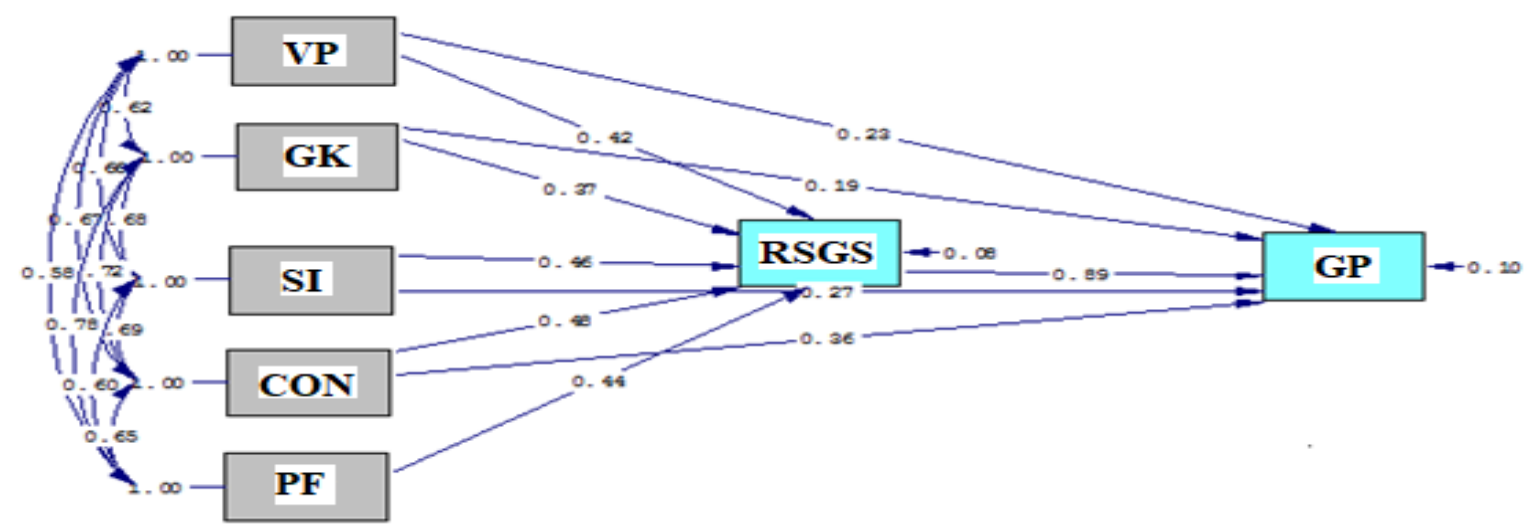

Figure 3. Standardized path coefficients for the new model

Figure 3 demonstrates that there was a positive effect between the visual mathematics literacy perception sub-dimensions. The fact that these values were greater than 0.50 indicated a high effect among the sub-dimensions. It was observed that there were a positive effects between RSGS and VP $(\beta 1=0.42)$, between RSGS and GK $(\beta 1=0.37)$, between RSGS and SI $(\beta 1=0.46)$, 
between RSGS and CON $(\beta 1=0.48)$ and between RSGS and PF $(\beta 1=0.44)$. Since these values were between 0.10 and 0.50 , it can be suggested that there was a moderate effect between the variables. Thus, it is possible to argue that the visual perception, geometry knowledge, spatial intelligence, concretization, and pattern formation skill levels of pre-service mathematics teachers had a moderate effect on reasoning skills on geometric shapes.

It was observed that there were positive effects between GP and VP $(\beta 1=0.23)$, between GP and GK $(\beta 1=0.19)$, between GP and SI $(\beta 1=0.27)$ and between GP and CON $(\beta 1=0.36)$. These values were between 0.10 and 0.50 and there was a moderate effect between the variables. Hence, it can be suggested that the visual perception, geometry knowledge, spatial intelligence and concretization skill levels of pre-service mathematics teachers had a moderate effect on their geometry performances.

It was observed that there was a positive effect between RSGS and GP $(\beta 1=0.89)$. Since this value was greater than 0.50 , it can be suggested that reasoning skills on geometric shapes levels of pre-service mathematics teachers had a high effect on their geometry performances. After the significance of the effects on variables was analyzed, direct, indirect, and aggregate effects of external variables on internal variables were investigated. Direct and indirect effects of the external variable VMLP and its sub-dimensions on the internal variables RSGS and GP are presented in Tables 3 and 4.

Table 3. Direct and indirect effects of external variables on RSGS

\begin{tabular}{llllll}
\hline Variable & Direct Effect $\left(\beta_{1}\right)$ & $\begin{array}{l}\text { Indirect } \\
\left(\beta_{2}\right)\end{array}$ & $\begin{array}{l}\text { Effect } \\
\text { VMLP }\end{array}$ Effect $^{{ }^{2}}$ & $\begin{array}{l}\text { Aggre } \\
\text { VIandard Error }\end{array}$ & Critical Ratio (t) \\
VP & 0,42 & 0,22 & 0,65 & 0,02 & $7,55^{*}$ \\
GK & 0,38 & 0,27 & 0,69 & 0,01 & $13,52^{*}$ \\
SI & 0,46 & 0,21 & 0,59 & 0,02 & $12,92^{*}$ \\
CON & 0,48 & 0,25 & 0,71 & 0,01 & $6,27^{*}$ \\
PF & 0,44 & 0,22 & 0,70 & 0,01 & $3,77^{*}$ \\
\hline
\end{tabular}

a: Aggregate Effect $=$ Direct Effect + Indirect Effect, $* \mathrm{p}<0,01$

Based on the structural regression model analysis results provided in Table 3, all subdimensions directly, positively, and significantly affected the reasoning ability on geometric shapes. In particular, the effect of CON sub-dimension was direct, positive, and significant on RSGS $(\beta 1=0.48, p<0.01)$. When the indirect effects were analyzed, it was observed that the effects were positive and moderate. When the aggregate effects on RSGA were analyzed, it can be suggested that since the aggregate effects of VMLP and its sub-dimensions on RSGS were greater than 0.50 , VMLP resources were highly important for RSGS.

Separate analysis of the sub-dimensions demonstrated that SI sub-dimension had the highest positive effect on RSGS (71\%). $46 \%$ of this effect was direct and $25 \%$ were indirect. Furthermore, the GK sub-dimension had a total effect of $59 \%$ on RSGS, 38\% of which was direct and $21 \%$ of which was indirect, and this sub-dimension had the lowest impact on RSGS. The other sub-dimensions had positive and moderate effects on RSGS. In total, VMLP had a $65 \%$ positive effect on RSGS, $43 \%$ of which was direct and $22 \%$ of which was indirect. In this study, the effects of external variables on Geometry Performance were analyzed based on the constructed model. The findings are presented in Table 4. 
Table 4. Direct and indirect effects of external variables on GP

\begin{tabular}{llllll}
\hline Variable & Direct Effect $\left(\beta_{1}\right)$ & $\begin{array}{l}\text { Indirect Effect } \\
\left(\beta_{2}\right)\end{array}$ & $\begin{array}{l}\text { Aggregate } \\
\text { Effect }^{{ }^{a}}\end{array}$ & $\begin{array}{l}\text { Standard } \\
\text { Error }\end{array}$ & Critical Ratio (t) \\
\hline VMLP & 0,32 & 0,25 & 0,57 & 0,02 & $4,84^{*}$ \\
VP & 0,23 & 0,23 & 0,46 & 0,01 & $7,69 *$ \\
GK & 0,19 & 0,17 & 0,36 & 0,01 & $5,12^{*}$ \\
SI & 0,27 & 0,24 & 0,51 & 0,02 & $3,29 *$ \\
CON & 0,36 & 0,28 & 0,64 & 0,01 & $1,92 *$ \\
PF & - & - & - & - & - \\
\hline
\end{tabular}

a: Aggregate Effect $=$ Direct Effect + Indirect Effect, ${ }^{*} \mathrm{p}<0,01$

Based on the structural regression model analysis results provided in Table 4 , the CON subdimension had a direct positive and significant effect on RSGS $(\beta 1=0.36, p<0.01)$. When the indirect effects of the sub-dimensions were analyzed, it was observed that they had moderate and positive effects. Analysis of the aggregate effects on GP demonstrated that VP, GK, SI and CON sub-dimensions and VMLP were very significant for GP.

Separate analysis of the sub-dimensions demonstrated that CON sub-dimension had the highest effect on GP with 64\%, 36\% of which was direct and $28 \%$ of which was indirect. The geometric knowledge sub-dimension had the lowest effect on geometry performance both directly (19\%) and indirectly (17\%). The other sub-dimensions had positive and moderate effects on GP. The total effect of VMLP on GP was $57 \%$ and positive, $32 \%$ of which was direct and $25 \%$ was indirect. In the study, after the effect sizes were analyzed, the fit index values for the dimension and sub-dimension models were investigated and the findings are presented in Table 5.

Table 5. Fit indices for the primary and sub-models

\begin{tabular}{lllll}
\hline Fit & Acceptable Fit & Good fit & $\begin{array}{l}\text { Fit Index } \\
\text { Primary / Sub Model }\end{array}$ & $\begin{array}{l}\text { Fit Index } \\
\text { Primary / Sub Model }\end{array}$ \\
\hline$x^{2} / d f$ & $2-3$ & $0-2$ & $0,44 / 0,49$ & Good / Good \\
\hline RMSEA & $0,05-0,08$ & $0-0,05$ & $0,00 / 0,01$ & Good / Good \\
\hline GFI & $0,90-0,95$ & $0,95-1,00$ & $0,96 / 0,94$ & Good / Acceptable \\
\hline AGFI & $0,85-0.90$ & $0,90-1,00$ & $0,92 / 0,89$ & Good /Acceptable \\
\hline RMSR & $0-0,05$ & $0-0,05$ & $0,04 / 0,05$ & Good / Good \\
\hline SRMSR & $0-0,05$ & $0-0,05$ & $0,01 / 0,01$ & Good / Good \\
\hline CFI & $0,95-0,97$ & $0,97-1,00$ & $0,97 / 0,98$ & Good / Good \\
\hline NNFI & $0,90-0,95$ & $0,95-1,00$ & $0,95 / 0,97$ & Good / Good \\
\hline
\end{tabular}

In Table 5, it was observed that $x^{2} / d f$ (Chi Square/Degree of Freedom) was 0.44 for the primary model and 0.49 for the sub-model. In light of this, it can be suggested that the primary and submodels exhibited a good fit. The RMSEA (Root Mean Square Error of Approximation) values, calculated for the primary and sub-model, were 0.00 and 0.01 and since these values were smaller than 0.05 , it can be suggested that both models exhibited good fit. When the GFI (Goodness-Of-Fit Index) values (0.96 / 0.94) were reviewed, it was witnessed that the value obtained for the primary model had good fit and the value obtained for the sub-model had acceptable fit. When AGFI (Adjusted Goodness of Fit Index) values (0.92 / 0.89) were analyzed, it was determined that the value obtained for the primary model had good fit and the value obtained for the sub-model had acceptable fit. RMSR (Root Mean Square Residual) values were 0,04 and 0,05 , and as these values were close to 0 , it can be suggested that both the primary model and the sub-model had good fit. SRMSR (Standardized Root Mean Square Residual) value is 0.01 for both the primary model and the sub-model and because this value was close to 0, it can be argued that the models had good fit. The CFI (Comparative Fit Index) values were calculated as 0.97 and 0.98 , respectively for both models, indicating a good fit. 
NNFI (Non-Normed Fit Index) values were 0.95 for the primary model and 0.97 for the submodel. These values evidenced that both primary and sub-models had good fit. The goodness of fit index statistics demonstrated that the primary and sub-models had acceptable and good fit. As a result, the constructed models were confirmed by the fit indices. In other words, it was seen that visual mathematics literacy perception and its sub-dimensions, which were proposed by the primary and sub-models, had significant effects on the reasoning skills on geometric shapes and geometry performance of pre-service mathematics teachers.

\section{Conclusion and Discussion}

The present study was conducted to investigate the correlation between visual mathematics literacy perceptions of pre-service mathematics teachers and their reasoning skills on geometric shapes and geometry performance levels with the path analysis method. For this purpose, a correlation matrix that reflected the correlations between the variables was constructed, path analysis was conducted between the visual mathematical literacy perception and its sub-dimensions and reasoning skills on geometric shapes and geometry performance, the direct, indirect and aggregate effects of visual mathematical literacy perception and its subdimensions on geometry performance and reasoning skills on geometric shapes were analyzed, and the models constructed for the primary and sub-dimensions were confirmed by fit indices.

Correlations between the study variables were analyzed before the construction of the models. A correlation matrix was developed to analyze the correlation between the variables. The findings demonstrated that all correlations between the variables were positive and significant. Analysis of the correlations between VMLP and its sub-dimensions demonstrated that there were positive and significant correlations between all sub-dimensions. Furthermore, it was observed that there was a moderate correlation between VMLP and RSGS, a moderate correlation between VMLP and GP, and a high correlation between RSGS and GP. In this vein, it could be suggested that there were correlations between VMLP, RSGS and GP of pre-service mathematics teachers. Also, these findings could be explained by the fact that the achievements of VMLP, RSGS and GP were similar. Literature review demonstrated that certain studies reported significant correlations between VMLP, RSGS and GP. Akyuz and Pala (2010) determined positive and high correlations between mathematics literacy, problem-solving and reasoning skills in a three-country model that included Turkish, Finnish and Greek Program for International Student Assessment (PISA) 2003 student survey data. In a study, Özdemir, Duran and Kaplan (2015) reported that problem-solving performance and reasoning skills of secondary school students and VMLP mutually predicted one another positively and significantly. Buckley, Seerey, and Canty (2019) reported that the skills of pre-service teachers to use spatial reasoning strategies increased after they solved geometry problems and their improved reasoning skills increased their performance in mathematics. In a study conducted by Areepattamannil (2014), a significant correlation between the performance of Indian adolescents in PISA and their metacognitive learning strategies (reasoning skills) was reported. In a study, Geer, Quinn and Ganley (2019) indicated that when growth variable was controlled, there was a correlation between spatial visualization skill in the first year and mathematics performance in the second year. Furthermore, mathematics performance in the second year predicted spatial visualization and spatial perception skills in the third year. Also, Çelik, Bindak and Özdemir (2018) determined that there was a high correlation between visual mathematics literacy perceptions of the students and their geometry achievements. However, there are also certain studies in the literature, which did not report a correlation between these variables, albeit a few. Ev Çimen and Aygüner (2018) reported that there was no significant correlation between visual mathematics literacy perception scale scores and actual performance test scores. 
In the study, to determine the direction, effect and significance of the correlations between the variables, a primary model was constructed between VMLP, RSGS and GP, and a subdimension model was constructed between VP-GK-SI-COM-PF sub-dimensions of VMLP, and between RSGS and GP. Analysis of the primary model demonstrated that there was a moderate correlation between VMLP and RSGS, and there was a strong correlation between RSGS and GP. Furthermore, there was a moderate effect between VMLP and GP. It was also determined that the effect sizes between the primary model variables were significant. However, analysis of the sub-model revealed that there were positive and significant effects between all VMLP sub-dimensions and RSGS, while there was a low and insignificant effect between the GP and PF sub-dimension, and there were moderate significant effects between GP and other subdimensions. In this directin, PF-GP path analysis was removed from the sub-dimension model, the model was reconstructed, and the path analyzes were conducted again. In the new model, it was determined that there was a positive, high level and significant effect between the subdimensions of VMLP. In other words, a positive, significant and strong effect was found between all sub-dimensions of the scale. This could be due to the accuracy of the scale, as well as the consistent responses of the pre-service mathematics teachers to the scale items. Literature review demonstrated similar findings. Çakmak (2013) analyzed the mathematical language (mathematics literacy) skills of eighth grade students with structural equation model and reported positive and significant effects between the sub-dimensions. Furthermore, İlhan (2015) determined that VMLP sub-dimensions affected each other significantly. Similarly, Kukey (2013) found that the sub-dimensions of mathematics literacy perception affected each other significantly.

In the study, analysis of the effects between VMLP sub-dimensions and RSGS demonstrated that there were moderate positive effects between VP and RSGS, GK and RSGS, SI and RSGS, CON and RSGS, and PF and RSGS. Furthermore, analysis of the primary model revealed that there was a moderate positive effect between VMLP and RSGS. This may be explained by the fact that pre-service mathematics teachers utilized their VMLP effectively for RSGS. In addition to that, this finding demonstrated that VMLP was effective on the development of accurate reasoning skills. Literature review revealed that certain studies emphasized a significant effect between mathematical or geometrical reasoning skills and mathematics literacy or visual mathematics literacy. Meaney (2007) reported that students' mathematical literacy significantly affected their mathematical thinking and reasoning skills. Yore, Pimm and Tuan (2007) determined that mathematical and scientific literacy components should not be neglected for the students and they emphasized the significance of cognitive and metacognitive skills (reasoning skills) in preparing the individuals for adult life.

In the study, analysis of the effects between VMLP sub-dimensions and GP demonstrated that there were moderate and positive effects between VP and GP, GK and GP, SI and GP, and $\mathrm{CON}$ and GP. Furthermore, analysis of the main study model revealed that there was a positive and moderate effect between VMLP and GP. This could be due to the fact that the performance of pre-service mathematics teacher candidates was consistent with their VMLP. Literature review revealed similar findings in previous studies. Kyttälä and Björn (2014) reported that literacy skills of the adolescents in mathematics problems affected their geometry performance and visual-spatial skills. Bates, Latham and Kim (2011) determined that mathematics literacy affected mathematical performance. Duran (2011) found that VMLP had a significant effect on visual mathematics achievements. Açıkbaş (2002) reported in a study that there were significant positive effects between mathematical performance of the students and their perceptions on their mathematical achievements. 
Furthermore, it was determined that there was a high-level positive effect between VMLP and GP. This could be due to the fact that accurate reasoning skills could lead to performance. There are former studies that reported similar findings. Şahin (2012) reported that geometric reasoning skills of pre-service mathematics teachers affected Van Hiele geometry performance level. Kyttälä and Lehto (2008) argued that active and passive visual-spatial working memory had a significant effect on mathematics performance. Furthermore, previous studies reported that mathematics performances (geometry, word problems, and mental arithmetic) were significantly influenced by fluid intelligence and visual-spatial working memory. In a study, Rapp (2009) reported that visual mental strategies (reasoning skills) increased and influenced achievement and performance levels. Furthermore, the study conducted with students with visual-spatial intelligence demonstrated that the performance level of the students with the above-mentioned traits decreased when the course was instructed with techniques that were not supported with visuals. Çelik and Özdemir (2011) reported that proportional reasoning skills had a significant impact on problem-posing performance in their study. Also, Çetin (2009) found that the proportional reasoning skills of eighth grade students had a high impact on equation solving performance.

The direct, indirect and aggregate effects of external variables on internal variables were investigated after the path analysis was conducted on the correlations between VMLP and its sub-dimensions, and RSGS and GP. Structural regression model analysis findings demonstrated that VP, GK, SI, CON and PF directly, positively and significantly affected RSGS. In particular, it was determined that the CON sub-dimension had a direct positive impact on RSGS. Furthermore, the overall VMLP had a direct, positive and significant effect on RSGS. Model analysis of the indirect effects on RSGS revealed that there were indirect and positive effects of VP, GK, SI, CON, PF and VMLP. Analysis of the aggregate effects on RSGS demonstrated that VP, GK, SI, CON, PF and VMLP were very important variables for RSGS. In other words, it is possible to suggest that both overall VMLP and its sub-dimensions had significant effects on RSGS. Literature review revealed that there were previous studies which reported the effects of mathematics literacy perception on reasoning skills. Özdemir, Duran and Kaplan (2015) reported that VMLP had a significant effect on the reasoning skills of secondary school students in their study. Similarly, Yore, Pimm and Tuan (2007) determined that the effects of mathematics literacy and reasoning skills were important for preparing individuals for life.

In the present study, after the analysis of the direct and indirect effects of external variables (VMLP and its sub-dimensions) on RSGS, direct and indirect effects of external variables on GP were analyzed. Structural regression model analysis findings demonstrated that VP, GK, SI, and CON directly, positively and significantly affected GP. In particular, CON subdimension had a significant positive effect on GP. Furthermore, the overall VMLP had a significant, direct and positive impact on GP. Model analysis of the indirect and total effects on GP demonstrated that VP, GK, SI, CON and VMLP had positive effects. In other words, VMLP and VP, GK, SI, CON sub-dimensions directly and indirectly impacted GP. Literature review demonstrated that there were studies which reported significant effects of mathematics literacy or VMLP on mathematical performance or GP. İlhan (2015) found that the VMLP of preservice mathematics teachers had a significant effect on their geometry performances. Similarly, Koğar (2015) identified in a study that mathematics literacy perception had a significant effect on mathematics performance.

In the study, after the direct and indirect effects of external variables on internal variables were analyzed, the fit indices were calculated for the model. In the present study, $x^{2} / s d$, RMSEA, GFI, AGFI, RMSR, SRMSR, CFI and NNFI index values were utilized. It was determined that 
the $x^{2} / s d$ reflected good fit for both the primary and sub-models. Literature review revealed similar findings. Chi-square statistics were used to concurrently compare nested models and to calculate other fit indices for the model. Jörekog and Sörbom (1993) suggested the comparison of the expected value for the sampling distribution using chi-square when investigating the fit indices and stated that chi-square/sd ratio should be $0 \leq x^{2} / s d \leq 2 \mathrm{df}$ for a good fit. The fact that the sample size was sufficiently large $(\mathrm{N}=384)$ increased the degree of freedom and thus decreased the $x^{2} / s d$ ratio. As reported by Kline (2011), a smaller $x^{2} / s d$ ratio would prove that the fit of the theoretical model would be good. Since the RMSEA obtained for the primary and sub-models were smaller than 0.05 , it was possible to suggest that both models exhibited a good fit. In other words, the RMSEA for the primary and sub-models were fit for the designed model and confirmed the model. Literature review revealed similar findings in previous studies. Çelik and Y1lmaz (2013) reported that RMSEA was a measure of approximate fit in the main mass, and when RMSEA is equal to or less than 0.05, there is a good fit, when it is between 0.05 and 0.08 , the fit is acceptable and when it is between 0.08 and 0.10 , the fit is mediocre.

In the study, GFI was calculated for the primary and sub-models and it was found to be close to one. The GFI obtained for the primary model revealed a good fit and the GFI for the submodel revealed an acceptable fit. Literature review revealed similar findings in previous studies. Schermelleh-Engel and Moosbrugger (2003) reported that if the GFI is greater than 0.90 , the fit is acceptable, and when it is 0.95 or greater, the fit is very good fit when compared to the basic model. AGFI was calculated for the primary model and the sub-model in the study. AGFI obtained for the primary model exhibited good fit and the AGFI for the sub-model exhibited acceptable fit. In other words, AGFI for both the main and sub-dimensions were sufficient to validate the model. Literature review revealed similar findings in previous studies. Loehlin (2004) reported that the AGFI should be greater than or equal to 0.85 and less than or equal to 1, and the model would exhibit good fit if it is greater than or equal to 0.90 . In the study, the RMSR was calculated for the primary and sub-models. Since the values obtained for the primary and sub-models were close to zero, it is possible to argue that both the primary model and the sub-model exhibited good fit. Literature review revealed similar findings in previous studies. Schermelleh-Engel and Moosbrugger (2003) reported that a RMSR value close to zero could be considered as a good fit. Also, Bollen (1989) stated that a RMSR value close to zero denotes a good fit, and RMSR should be less than or equal to 0.05 .

In the study, it was found that SRMSR was very close to zero for both the primary and submodels. Therefore, it is possible to suggest that both models exhibited good fit. Literature review revealed similar findings in previous studies. Hu and Bentler (1999) argued that a SRMSR close to zero can be considered a good fit. Similarly, Loehlin (2004) reported that as SRMSR value approaches zero, there would be a good fit, and the value should be less than or equal to 0.05 . In the study, the CFI was calculated for the primary and sub-models. Since the CFI for both models were close to one, it can be suggested that both primary and sub-models exhibited good fit. Literature review displayed similar findings in previous studies. Brown (2006) reported that CFI takes values between zero and one, and if the value approaches to one, then the model exhibits good fit. Finally, NNFI values were calculated individually for the primary and sub-models and it was determined that both were close to one. NNFI values indicated that the fit of the primary and sub-models was good. Literature review revealed similar findings in previous studies. Çelik and Yılmaz (2013) reported that NNFI takes values between zero and one in their study and that the fit of the model is good as NNFI approaches one. The goodness of fit indices for the above-mentioned models demonstrated that the models exhibited acceptable or good fit (Bollen, 1989; Jöreskog and Sörbom, 1993; Hu and Bentler, 1999; Schermelleh-Engel and Moosbrugger, 2003; Loehlin, 2004; Brown, 2006 Kline, 2011; 
Çelik and Y1lmaz, 2013). Thus, arguably the constructed models were confirmed by the abovementioned data. In other words, it was determined that the effects of VMLP and its subdimensions on RSGS and GP were significant.

In conclusion, analysis of the correlations between VMLP and its sub-dimensions, and RSGS and GP demonstrated positive and significant correlations between all variables. In the primary model, which was constructed in order to obtain more detailed information on the direction, magnitude and effect of these correlations, it was determined that there were moderate and significant correlations between VMLP and RSGS and VMLP and GP, and there was a high and significant correlation between RSGS and GP. Analysis of the direct, indirect and aggregate effects of external variables on internal variables revealed that VMLP and its sub-dimensions had positive, direct, indirect and aggregate effects on RSGS and GP. Furthermore, the fit indices were calculated for the models constructed in the study, and the fit indices for the correlations between the variables were determined as acceptable or good, and the constructed models were confirmed.

The following recommendations are presented based on the study findings:

- The study was conducted with pre-service mathematics teachers and it was found that there were positive and significant correlations and effects between VMLP, RSGS and GP. Thus, future studies could be conducted with middle school mathematics teachers, secondary education mathematics teachers or academicians working in the field of mathematics education.

- In the present study, the correlations between VMLP, RSGS and GP associated with geometry, which is a mathematics learning area, were investigated. For other learning areas (numbers and operations, data processing, probability and algebra) considered as the backbone of the mathematics curriculum, the correlations between literacy, reasoning and performance could be re-investigated with similar or different statistical methods.

- In the study, the concepts of VMLP, which is a combination of visual literacy and mathematics literacy, RSGS, which is a combination of geometry and reasoning skills, and GP, which is a combination of geometry and performance, were scrutinized. VMLP, RSGS and GP concepts could be integrated in new mathematics curriculum that would be developed in this direction.

\section{References}

Açıkbaş, N. (2002). The Relationship between mathematics performance, attitudes toward mathematics, grade level and gender. Published Master's Thesis, Boğaziçi University, Institute of Natural and Applied Sciences, İstanbul.

Akyüz, G. \& Pala, N. M. (2010). The effect of student and class characteristics on mathematics literacy and problem solving in PISA 2003. Elementary Education Online, 9(2), 668678 .

Alpan, G. (2008). Visual literacy and instructıonal technology. Yüzüncü Yıl University Journal of Education Faculty, 5(2), 74-102.

Amsterlaw, J. (2004). Children's beliefs about everyday reasoning. Published Doctoral Thesis, University of Michigan. Available from ProQuest Dissertations and Theses Database, (UMI Microform 3138102).

Areepattamannil, S. (2014). What factors are associated with reading, mathematics and science literacy of Indian adolescents? A multilevel examination. Journal of Adolescence, 37(4), 367-372. 
Baki, A. (2001). Evaluation of mathematics education in the light of information technology. Journal of Ministry of National Education, 149(1), 26-31.

Bal A. P. (2012). Primary school students' views and challenges on performance task preparation process in mathematics course. Pegem Journal of Education and Instruction, 2(1), 11-23.

Bates, A. B., Latham, N., \& Kim, J. A. (2011). Linking preservice teachers' mathematics selfefficacy and mathematics teaching efficacy to their mathematical performance. School Science and Mathematics, 111(7), 325-333.

Battista, M. T. (1994). On Greene's environmental/model view of conceptual domains: A spatial/geometric perspective. Journal for Research in Mathematics Education, 25(1), 86-99.

Baykul, Y. (2014). Teaching mathematics in primary school (5-8. Classes) (12th Edition). Ankara: Pegem Academy Publishing.

Bekdemir M. \& Duran, M. (2012). Development of a visual math literacy self efficacy perception scale (VMLSEPS) for elementary students. On Dokuz Mayls University Journal of Education Faculty, 31(1), 89-115.

Bentler, P. M. \& Chou, C. P. (1987). Practical issues in structural modeling. Sociological Methods \& Research, 16(1), 78-117.

Bollen, K. A. (1989). Structural equations with latent variable. New York: Wiley Publisher.

Brown, T. A. (2006). Confirmatory factor analysis for applied research. New York: The Guilford Press.

Buckley, J., Seery, N., \& Canty, D. (2019). Investigating the use of spatial reasoning strategies in geometric problem solving. International Journal of Technology and Design Education, 29(2), 341-362.

Büyüköztürk, Ş. (2015). Data analysis handbook for social sciences (10th edition). Ankara: Pegem Academy Publishing.

Chen, X., Dipinto, V., \& Newman, M. (2017). Faculty research residency report: Teachers' visual literacy practices in middle and high school science classrooms. NCE Research Residencies, 10(1), 1-32.

Clements, D. \& Battista, M. (1992). Geometry and spatial reasoning. In D. A. Grows (Ed.), Handbook of research on mathematics teaching and learning: A project of the National Council of Teachers of Mathematics (pp. 420-464), New York, NY, England Macmillan Publishing.

Çakmak, Z. (2013). An investigation of the variables related to 8th grade students' mathematical language skills in statistics through structural equitation model. Published Master's Thesis, Erzincan University, Institute of Natural and Applied Sciences, Erzincan.

Çalışkan, M. (2016). Researching the effects of the instruction of the solid matters assisted with dynamic geometry softwares on the 7th graders' attitudes towards geometry and spatial thinking. Published Master's Thesis, Dokuz Eylül University, Institute of Educational Sciences, İzmir.

Çelik, H. C. Bindak, R., \& Özdemir, F. (2018). Development of a vısual mathematıcs literacy scale and investigation of visual mathematics literacy perception according to various varıbles. In: Y. K., Yeke, T., Yazıcı \& O., Hayırlı (Eds.), Innovative Approaches in Educatıonal Sciences (pp. 63-76), Ankara: Gece Academy.

Çelik, A. \& Özdemir, E. Y. (2011). The relationship between elementary school students' proportional reasoning skills and problem posing skills involving ratio and proportion. Pamukkale University Journal of Education Faculty, 30(1), 1-11.

Çelik, E. H. \& Y1lmaz, V. (2013). Structural equation modeling with LISREL 9.1, basic concepts-applications-programming (2th edition). Ankara: Anı Publishing. 
Çetin, H. (2009). A study on the relation between proportional reasoning skills and the successes of solving equation of elementary school secondary stage students. Published Master's Thesis, Selçuk University, Institute of Natural and Applied Sciences, Konya.

Duran, M. (2011). Relationship between visual math literacy self efficacy perceptions with visual mathematic achievements of elementary 7th grade students. Published Master's Thesis, Erzincan University, Institute of Natural and Applied Sciences, Erzincan.

Duran, M. \& Bekdemir, M. (2013). Evaluation of visual math literacy self efficacy perception with visual mathematics accomplishment. Pegem Journal of Education and Instruction, $3(3), 27-40$.

Durmuş, S., Toluk-Ucar, Z., \& Olkun, S. (2002). Determining the geometry field knowledge levels of first year students of mathematics teaching, researches and results for the improvement of the levels. V. National Science and Mathematics Education Congress, 16-18 September, Ankara, p. 224.

Erdoğan, T. (2006). The Effect of Van hiele model based instruction process on primary candidate teachers' level of readiness towards new geometry subjects. Published Master's Thesis, Abant İzzet Baysal University, Institute of Social Sciences, Bolu.

Ev Çimen, E. \& Aygüner, E. (2018). An analysis of eight grade students' self-efficacy perception of visual mathematics literacy and their actual performance. Elementary Education Online, 17(2), 675-696.

Gallant, D. J. (2009). Predictive validity evidence for an assessment program based on the Work Sampling System in mathematics and language and literacy. Early Childhood Research Quarterly, 24(2), 133-141.

Geer, E. A., Quinn, J. M., \& Ganley, C. M. (2019). Relations between spatial skills and math performance in elementary school children: A longitudinal investigation. Developmental Psychology, 55(3), 637-652.

Güleş, H. K., Akgemci, T., \& Türkmen, M. (2011). Strategic production business performance relationship: an analysis on structural equation modeling. Istanbul University Faculty of Economics Journal of Econometrics and Statistics, 13(2011), 62-79.

Hair, J. F., Black, W. C., Babin, B. J., \& Anderson, R. E. (1998). Multivariate Data Analysis a global perspective (Seventh Edition). New Jersey: Prentice-Hall International Inc.

Hohenwarter, M. \& Preiner, J. (2007). Dynamic mathematics with GeoGebra. The Journal of Online Mathematics and its Applications, 7(1). 1-21.

Hu, L. \& Bentler, P. M. (1999). Cutoff criteria for fit indexes in covariance structure analysis: Conventional criteria versus new alternatives. Structural Equation Modeling: A Multidisciplinary Journal, 6(1), 1-55.

İlhan, A. (2015). Development of visual mathematics literacy scale towards elementary school mathematics teacher candidates and investigation of the relationship between success in geometry and visual mathematics literacy. Published Master's Thesis, Firat University, Institute of Educational Sciences, Elazığ.

İlhan, A. (2019). Investigation of the relationship of elementry mathematics teacher candidates' between visual mathematics literacy perception level, reasoning skill on geometry and performance levels. Published Doctoral Thesis, İnonu University, Institute of Educational Sciences, Malatya.

İlhan, A. \& Aslaner, R. (2018). Examination of mathematics teacher candidates' reasoning skills on geometric shapes in terms of university and class level variables. Inönü University Journal of the Faculty of Education, 19(2), 82-97.

Jadallah, M. (2009). Teacher scaffolding moves and children's talk in collaborative reasoning discussions. Publishing Doctoral Thesis, University of Illinois, Available from ProQuest Dissertations and Theses database (UMI Microform 3392077). 
Jayaram, J., Kannan, V. R., \& Tan, K. C. (2004). Influence of initiators on supply chain value creation. International Journal of Production Research, 42(20), 4377-4399.

Jöreskog, K. G. \& Sörbom, D. (1993). LISREL 8 user's reference guide. Chicago: Scientific Software International.

Karadăg, E., Baloğlu, N., \& Küçük, E. (2010). The effects of the principal supervision' perception to work motivation of teachers: a study of path analysis. Turkish Journal of Educational Sciences, 8(2), 417-437.

Karasar, N. (1999). Scientific research methods. Ankara: Nobel Publication Distribution.

Keskin, S. (1998). Path coefficients and path analysis. Published Master's Thesis, Ankara University, Institute of Natural and Applied Sciences, Ankara.

K1liç, S. (2015). Kappa test. Journal of Mood Disorders, 5(3), 142-144.

Kline, R. B. (2011). Principles and practice of structural equation modeling (Third Edition). New York: The Guilford Press.

Kocakaya, S. (2008). Investigation of relations among the factors that affect physics course achievement of high school students using path analysis technique. Published Doctoral Thesis, Dicle University, Institute of Natural and Applied Sciences, Diyarbakır.

Koğar, H. (2015). Examination of factors affecting PISA 2012 mathematical literacy through mediation model. Journal of Education and Science, 40(179), 45-55.

Konyalığlu, A. C. (2003). Investigation of effectiveness of visualization approach on understanding of concepts in vector spaces at the university level. Unpublished Doctoral Dissertation, Atatürk University, Institute of Natural and Applied Sciences, Erzurum.

Kukey, E. (2013). The effects of the mathematics literacy level of the secondary school 8th grade students to mathematics achievement. Published Master's Thesis, Firat University, Institute of Educational Sciences, Elazı̆̆.

Kurtz, K. J., Gentner, D., \& Gunn, V. (1999). Reasoning: Handbook of perception and cognition. San Diego: Academic Press.

Kyttälä, M. \& Lehto, J. E. (2008). Some factors underlying mathematical performance: The role of visuospatial working memory and non-verbal intelligence. European Journal of Psychology of Education, 23(1), 77-94.

Kyttälä, M. \& Björn, P. M. (2014). The role of literacy skills in adolescents' mathematics word problem performance: Controlling for visuo-spatial ability and mathematics anxiety. Learning and Individual Differences, 29(1), 59-66.

Loehlin, J. C. (2004). Latent variable models: an introduction to factor, path, and structural analysis. Mahwah, New Jersey, London: Lawrence Erlbaum Associates, Publishers.

Meaney, T. (2007). Weighing up the influence of context on judgements of mathematical literacy. International Journal of Science and Mathematics Education, 5(1), 681-704.

Ministry of National Education [MoNE] (2005). Elementary mathematics lesson 1-8. classes curriculum. Ankara: Board of Education and Training.

Ministry of National Education [MoNE] (2009). Secondary mathematics lesson 5-8. classes curriculum. Ankara: Board of Education and Training.

Ministry of National Education [MoNE] (2011). Secondary mathematics lesson 5-8. classes curriculum. Ankara: Board of Education and Training.

Ministry of National Education [MoNE] (2013). Secondary mathematics lesson 5-8. classes curriculum. Ankara: Board of Education and Training.

Ministry of National Education [MoNE] (2017). Board of education and training, mathematics teacher special field competencies. Retrieved from http://otmg.meb.gov.tr/alanmatematik.html at 02.04.2019.

Ministry of National Education [MoNE] (2018). Primary and secondary school mathematics 1-8. classes curriculum. Ankara: Board of Education and Training. 
Oaksford, M. (2005). Reasoning. In Nick B. \& Angus G., Cognitive psychology (pp. 1-744) New York: Oxford University Press Inc.

Olkun, S. (2003). Making Connections: 1mproving spatial abilities with engineering drawing activities. International Journal of Mathematics Teaching and Learning, Aprll(1), 1-10.

Özdemir, F., Duran, M., \& Kaplan, A. (2015). Investigation of middle school students' selfefficacy perceptions of visual mathematics literacy and perceptions of problem-solving skill. Journal of Theoretical Educational Science, 9(4), 532-554.

Özsoy, G. (2005). The relationship between problem solving skills and mathematical achievement. Journal of Gazi University Education Faculty, 25(3), 179-190.

Pajares, F. \& Kranzler, J. (1995). Self-efficacy beliefs and general mental ability in mathematical problem-solving. Contemporary Educational Psychology, 20(1), 426443.

Paksu, A. D. (2013). Investigation of preservice elementary teachers' abilities on drawing geometric construction. Kastamonu Education Journal, 21(3), 827-840.

Pellegrino, J. W., Alderton, D. L., \& Shute, V. J. (1984). Understandings patialability. Educational Psychologist, 19(3), 239-253.

Rapp, W. H. (2009). Avoiding math taboos: Effective math strategies for visual-spatial learners. Journal of Teaching Exceptional Children Plus, 6(2), 2-12.

Schermelleh-Engel, K., Moosbrugger, H., \& Müller, H. (2003). Evaluating the fit of structural equation models: Test of significance and descriptive goodness-of-fit measures. Methods of Psychological Research Online, 8(2), 23-74.

Suhr, D. (2009). Guidelines for reliability, confirmatory and exploratory factor analysis. Western Users of SAS Software Conference Proceedings. Retrieved from, https://www.lexjansen.com/wuss/2009/anl/ANL-SuhrShay.pdf at 15.09.2020.

Şahin, Y. (2012). An investigation on geometric reasoning of pre-service elementary mathematics teachers in terms of some variables. Published Master's Thesis, Hacettepe University, Institute of Educational Sciences, Ankara.

Umay, A. Duatepe, A., \& Akkus-C1kla, O. (2005). Readiness levels for new mathematical content in the curriculum of primary teacher candidates. XIV. National Educational Sciences Congress Pamukkale University, Faculty of Education, 28-30 September, Denizli, 456-458.

Webb, N. L. (1993). Assessment in the mathematics classroom. Reston, VA: NCTM.

Yore, L. D., Pimm, D., \& Tuan, H. L. (2007). The literacy component of mathematical and scientific literacy. International Journal of Science and Mathematics Education, 5(4), 559-589. 